\title{
Global macroeconomic repercussions of US trade restrictions: Evidence from a GVAR model
}

\author{
Revised version May 25, 2019
}

\begin{abstract}
We employ a global vector autoregression (GVAR) model to analyze international spillover effects of US trade restrictions, modeled as a reduction of US imports. Our sample consists of the US and 25 countries in the rest of the world, grouped into larger regions comprising European nations, non-European industrial countries and emerging economies. We find US trade restrictions to reduce trade volumes and income levels in the rest of the world as well as in the US. The trade balance deteriorates across all world regions except in the US, where it is unaffected by the trade restrictions. We also model the effects of a trade war in which the rest of the world responds in equal measure to the trade restrictions imposed by the US. We again find that export and import activity recedes both in the US and in the rest of the world, although the resulting effects are now strongest in the short run. The trade balance improves in the rest of the world but deteriorates in the US. In terms of the GDP response, the rest of the world is initially much harder hit by the imposition of the retaliatory trade measure than is the US.
\end{abstract}

Keywords: Trade restrictions; International spillover effects; Global vector autoregression; Trade war

JEL Classification: C32, F14, F42

Word count: 5231 words 


\section{Introduction}

The main motive behind the increasingly protectionist US trade policy appears to be the intention of sheltering the American economy from supposedly unfair trade practices in the rest of the world. Proponents of this strategy hope to bring back jobs to the US economy, thereby fostering economic growth. Another stated goal of this policy is to reduce the perennial current account and trade deficits of the US economy. Whereas most standard trade models unambiguously point to the detrimental effects of protectionism, assessing whether restrictive trade policy measures are successful in the sense mentioned above is ultimately an empirical matter. However, any such assessment is incomplete if the focus is on the US economy alone. Rather, quantifying the potential macroeconomic effects of US trade restrictions on the American economy requires taking into account their international repercussions with the rest of the world.

We employ the global vector autoregression (GVAR) model pioneered by Pesaran et al. (2004) and Dees et al. (2007) to capture the international transmission and international repercussions of US trade policy shocks ${ }^{1}$. We also investigate the scenario of a trade war in which the rest of the world imposes retaliatory tariff measures. A number of studies uses the GVAR technique to model the interconnectedness of the US economy with the rest of the world. Recent papers focus on the international spillovers of financial stress shocks (Dovern and van Rohe (2014)), aggregate demand, supply and monetary policy shocks (Feldkircher and Huber (2016)), credit supply shocks (Eickmeier and Ng (2015)) and loan

\footnotetext{
${ }^{1}$ There is a large and growing literature employing GVAR analysis to study international spillover effects. Chudik and Pesaran (2016) provide an overview of recent developments in GVAR modeling with respect to both the theoretical foundations and its numerous empirical applications.
} 
supply and demand shocks (Fadejeva et al. (2017)). Closest to our analysis are the papers by Bussiére et al. (2012) and Greenwood-Nimmo et al. (2012), who apply the GVAR technique to investigate the factors behind the dynamics of global trade flows. Whereas these papers are primarily concerned with the issue of global imbalances and their unwinding, we apply the GVAR analysis to investigate the international transmission of original trade policy shocks. Moreover, in order to identify the shocks better, structural generalized impulse response functions (SGIRFs) are used for the dynamic analysis instead of commonly used generalized impulse response functions (GIRFs). This goes beyond most previous studies to identify shocks and at least partially overcomes one of the main criticisms regarding identification and the use of GIRF's in GVAR models.

In this paper, we analyze international spillover effects of US trade restrictions, modeled as a general reduction of US import volumes, as well as potential retaliatory measures imposed in the rest of the world. To this end, we consider the US as well as 25 of its top trading partner countries. Rather than analyzing the transmission effects for each of these countries in isolation, we proceed as Feldkircher and Huber (2016) in reporting the effects for larger regions, in our case comprising European nations, non-European industrial countries and emerging economies. We follow Bussiére et al. (2012) by setting up the GVAR model with data on real exports and imports as the main variables of interest. Moreover, we include real output and the effective real exchange rate representing the demand and relative price terms respectively. Finally, we also include the price of oil as a global variable.

Previewing our results, we find that a negative shock to US imports reduces trade volumes and income levels in the rest of the world as well as in the US itself. The trade balance deteriorates in all world regions except in the US where it remains essentially unchanged in 
the face of the trade restriction. However, we find no significant real exchange rate responses in the US or in the rest of the world. In the trade war scenario we assume that the rest of the world imposes import restrictions in response to the US trade barriers. We again find that export and import activity recedes both in the US and in the rest of the world, although the resulting effects are now strongest in the short run. The trade balance improves in the rest of the world but deteriorates in the US. In terms of the GDP response, the rest of the world is initially much harder hit by the imposition of the retaliatory trade measure than is the US.

The remainder of the paper is structured as follows: section 2 introduces the GVAR model, section 3 describes the data and reports on some of their statistical properties which need to be satisfied as a prerequisite to apply the GVAR methodology, section 4 discusses the results by means of impulse response analysis, and section 5 concludes.

\section{The GVAR model}

The GVAR methodology constitutes a simple yet rigorous way to analyze interdependencies across economies or regions in a multi-country setting. The GVAR model is implemented in two steps. In a first step separate VAR or VECM models are estimated for each individual country or region. These models are augmented by appropriately weighted averages of corresponding weakly exogenous foreign variables, and are referred to as VARX models. In a second step the individual VARX models are combined in a consistent manner by means of a link matrix to build and simultaneously solve the global model.

Denote $N+1$ as the number of countries or regions in the model indexed by $i=$ $0,1,2, \ldots . . N$, with $i=0$ as the reference country and $t=1, \ldots, T$ denoting time. The 
individual country or regional VARX $\left(q_{i}, q_{i}^{*}\right)$ models are given by:

$$
\boldsymbol{x}_{i, t}=\boldsymbol{a}_{i, 0}+\boldsymbol{a}_{i, 1} t+\sum_{m=1}^{q_{i}} \boldsymbol{\phi}_{i, m} \boldsymbol{x}_{i, t-m}+\sum_{n=0}^{q_{i}^{*}} \boldsymbol{\Lambda}_{i, n} \boldsymbol{x}_{i, t-n}^{*}+\boldsymbol{u}_{i, t}
$$

with $\boldsymbol{x}_{i, t}$ a $k_{i} \times 1$ vector of region- $i$ endogenous domestic variables and $\boldsymbol{x}_{i, t}^{*}$ a $k_{i}^{*} \times 1$ vector of the corresponding weakly exogenous foreign variables, where $\phi_{i}$ and $\boldsymbol{\Lambda}_{i}$ are $k_{i} \times k_{i}$ and $k_{i} \times k_{i}^{*}$ coefficient matrices associated with the domestic and foreign variables respectively. Moreover, $\boldsymbol{a}_{i, 0}$ is a $k_{i} \times 1$ vector of fixed intercepts, $\boldsymbol{a}_{i, 1}$ is a $k_{i} \times 1$ vector on the deterministic time trends, and $\boldsymbol{u}_{i}$ is a $k_{i} \times 1$ vector of region-specific shocks, where $\boldsymbol{u}_{i} \sim \mathrm{N}\left(0, \sum_{i i}\right)$, and $\sum_{i i}$ is a non-singular covariance matrix. Region-specific shocks are assumed to be serially uncorrelated, but cross-regional correlations between entities $i$ and $j$ among the idiosyncratic shocks are allowed for, so that $E\left(\boldsymbol{u}_{i, t}, \boldsymbol{u}_{j, s}^{\prime}\right)=\sum_{i j}$ for $t=s$, and $E\left(\boldsymbol{u}_{i, t}, \boldsymbol{u}_{j, s}^{\prime}\right)=\mathbf{0}$ for $t \neq s$.

The vector of foreign region-specific variables, $\boldsymbol{x}_{i, t}^{*}$, is obtained from weighted averages of each variable across all other countries of the sample. More specifically, for any $i, j=$ $0,1, \ldots, N$

$$
\boldsymbol{x}_{i, t}^{*}=\sum_{j=0}^{N} w_{i, j} \boldsymbol{x}_{j, t}
$$

where $w_{i, j}$ is a weighting factor that captures the importance of region $j$ for region $i$, with $\sum_{j=0}^{N} w_{i, j}=1$ and $w_{i, i}=0$. We follow standard practice by using as weights the fixed trade shares between countries.

Setting $p_{i}=\max \left(q_{i}, q_{i}^{*}\right)$, the model of Eq. (1) can be rewritten as 


$$
\boldsymbol{A}_{i, 0} z_{i, t}=\boldsymbol{a}_{i, 0}+\boldsymbol{a}_{i, 1} t+\sum_{m=1}^{p_{i}} \boldsymbol{A}_{i, m} \boldsymbol{z}_{i, t-m}+\boldsymbol{u}_{i, t}
$$

where the $\left(k_{i}+k_{i}^{*}\right) \times 1$ vector $\boldsymbol{z}_{i, t}=\left(\boldsymbol{x}_{i, t}{ }^{\prime}, \boldsymbol{x}_{i, t}^{*}{ }^{\prime}\right)^{\prime}$ contains both the domestic and foreign variables, and where the $k_{i} \times\left(k_{i}+k_{i}^{*}\right)$ coefficient matrices are given by $\boldsymbol{A}_{i, 0}=\left(\boldsymbol{I}_{k_{i}},-\boldsymbol{\Lambda}_{i, 0}\right)$ and $\boldsymbol{A}_{i, m}=\left(\boldsymbol{\phi}_{i, m}, \boldsymbol{\Lambda}_{i, m}\right)$ for $m=1, \ldots, p_{i}$.

In order to allow for co-integrating relationships within and between regions, the individualregion VARX models of Eq. (1) can also be estimated in error-correction form:

$$
\Delta \boldsymbol{x}_{i, t}=\boldsymbol{c}_{i, 0}-\boldsymbol{\alpha}_{i} \boldsymbol{\beta}_{i}^{\prime}\left(\boldsymbol{z}_{i, t-1}-\gamma_{t}(t-1)\right)+\boldsymbol{\Lambda}_{i, 0} \Delta \boldsymbol{x}_{i, t}^{*}+\sum_{m=1}^{p_{i}-1} \boldsymbol{\Gamma}_{i, m} \Delta \boldsymbol{z}_{i, t-m}+\boldsymbol{u}_{i, t} \cdot(4)
$$

Here $\boldsymbol{\alpha}_{i}$ is a $k_{i} \times r_{i}$ loading matrix and $\boldsymbol{\beta}_{i}$ is a $\left(k_{i}+k_{i}^{*}\right) \times r_{i}$ matrix of coefficients of the long-run equilibrium, with $r_{i}$ denoting the co-integration rank between $\boldsymbol{x}_{i}$ and $\boldsymbol{x}_{i}^{*}$ for region $i$.

Next the regional-specific variables are stacked in a single $k \times 1$ vector $\boldsymbol{x}_{t}=\left(\boldsymbol{x}_{0, t}^{\prime}, \boldsymbol{x}_{0,1}^{\prime}, \ldots, \boldsymbol{x}_{N, t}^{\prime}\right)^{\prime}$ with $k=\sum_{j=0}^{N} k_{j}$, and linked by means of region-specific $\left(k_{i}+k_{i}^{*}\right) \times k$ matrices collecting the individual trade weights $w_{i, j}$. These link matrices are of the form

$$
\boldsymbol{W}_{i}=\left[\begin{array}{ccccc}
\mathbf{0}_{k_{i}} & \ldots & \boldsymbol{I}_{k_{i}} & \ldots & \boldsymbol{0}_{k_{i}} \\
w_{i, 0} \boldsymbol{I}_{k_{i}^{*}} & \ldots & w_{i, i} \boldsymbol{I}_{k_{i}^{*}} & \ldots & w_{i, N} \boldsymbol{I}_{k_{i}^{*}}
\end{array}\right]
$$

and are constructed to yield the identity $\boldsymbol{z}_{i, t}=\boldsymbol{W}_{i} \boldsymbol{x}_{t}$. From Eq. (3) it follows that

$$
\boldsymbol{A}_{i, 0} \boldsymbol{W}_{i} \boldsymbol{x}_{t}=\boldsymbol{a}_{i, 0}+\boldsymbol{a}_{i, 1} t+\sum_{m=1}^{p_{i}} \boldsymbol{A}_{i, m} \boldsymbol{W}_{i} \boldsymbol{x}_{t-m}+\boldsymbol{u}_{i, t} .
$$


Stacking the $N+1$ systems in Eq. (6) yields the global model

$$
\boldsymbol{G}_{0} \boldsymbol{x}_{t}=\boldsymbol{a}_{0}+\boldsymbol{a}_{1} t+\sum_{m=1}^{p} \boldsymbol{G}_{m} \boldsymbol{x}_{t-m}+\boldsymbol{u}_{t}
$$

with $\mathbf{a}_{0}=\left(\boldsymbol{a}_{00}, \boldsymbol{a}_{10}, \ldots, \boldsymbol{a}_{N 0}\right), \boldsymbol{a}_{1}=\left(\boldsymbol{a}_{01}, \boldsymbol{a}_{11}, \ldots, \boldsymbol{a}_{N 1}\right), \boldsymbol{u}_{t}=\left(\boldsymbol{u}_{0 t}, \boldsymbol{u}_{1 t}, \ldots, \boldsymbol{u}_{N t}\right)$,

and where $\mathbf{G}_{m}=\left(\boldsymbol{A}_{0 m} \boldsymbol{W}_{0}, \boldsymbol{A}_{1 m} \boldsymbol{W}_{1}, \ldots, \boldsymbol{A}_{N m} \boldsymbol{W}_{N}\right)$

for $m=1, \ldots, p$ and $p=\max \left(p_{0}, \ldots, p_{N}\right)$.

With $\boldsymbol{G}_{0}$ a non-singular $k \times k$ matrix that depends only on the known trade weights and parameter estimates, the $\operatorname{GVAR}(p)$ model is finally obtained after pre-multiplying Eq. by $G_{0}^{-1}$ :

$$
\boldsymbol{x}_{t}=\boldsymbol{b}_{0}+\boldsymbol{b}_{1} t+\sum_{m=1}^{p} \boldsymbol{F}_{m} \boldsymbol{x}_{t-m}+\boldsymbol{\varepsilon}_{t}
$$

with $\boldsymbol{b}_{0}=\boldsymbol{G}_{0}^{-1} \boldsymbol{a}_{0}, \boldsymbol{b}_{1}=\boldsymbol{G}_{0}^{-1} \boldsymbol{a}_{1}, \boldsymbol{F}_{m}=\boldsymbol{G}_{0}^{-1} \boldsymbol{G}_{m}$ for $m=1,2, \ldots, p$ and $\boldsymbol{\varepsilon}_{t}=\boldsymbol{G}_{0}^{-1} \boldsymbol{u}_{t}$.

\section{Data and model specification}

We use data on the US as well as 25 of its top trading partners. These are grouped into larger regions of European nations (EC), non-European industrial countries (NE) and emerging economies (EE). The first group consists of the 7 EU countries Belgium, France, Germany, Ireland, Italy, the Netherlands and Spain plus the UK and Switzerland. The group of nonEuropean industrial countries is made up of Australia, Canada, Chile, Hong Kong, Japan, Singapore and South Korea. Finally, the emerging markets group includes Brazil, China, India, Indonesia, Malaysia, Mexico, Russia and Thailand. We use quarterly data spanning 
the time period from 1992Q1 to 2017Q4 on real exports and imports, real output, the effective real exchange rate and the price of Brent crude oil, in the following denoted as EX, IM, GDP, REER and OIL respectively. The data for GDP, EX, IM and OIL come from Oxford Economics, and for REER from IMF International Financial Statistics, where all data were collected from Datastream. Whenever seasonally adjusted data were not available, they were adjusted using the census X-12 method. Regional variables for the core and periphery groups were constructed using the aggregator

$$
y_{t}=\sum_{i=1}^{N} \omega_{i} y_{i, t}
$$

where $y_{t}$ denotes a regional variable, $y_{i, t}$ is the value of that variable for country $i$, and $\omega_{i}$ represents the relative importance of country $i$ within the region. Following Dees et al. (2007), $\omega_{i}$ is computed by dividing the PPP-GDP figure of each country by the total sum across the $N$ countries of the region, such that their weights add up to unity.

[Figure 1 about here]

Fig.1 visualizes the time series of GDP, EX, IM and REER for the four regions of the sample. The raw data show the GDP growth rates of both the EE and NE regions to have been substantially stronger throughout the sample period in comparison to either the US or the EC. Similar evidence obtains for the EX and IM series, where the accelerating pace of globalization since the 1990s boosted trade flows across all regions, and particularly so in the EE and NE country groups. The graphs also show that the financial crisis of 2008-09 induced a substantial downward shift of the levels of GDP and the trade flow variables, 
but did not materially affect the long-run growth rates of these series, which have mostly returned to their pre-crisis growth clips. Finally, the REER series display some persistent swings, especially for the US real exchange rate with its substantial appreciation in the early 2000s, its drawn-out phase of gradual depreciation throughout the 2000s and early 2010s, as well as its renewed appreciation in the most recent years of the sample. Correspondingly, the periods of relative strength of the US dollar are reflected in a comparative weakness of the REERs in the other world regions, particularly in the EC and the emerging economies.

We checked for stationarity of the data for the region-specific variables and their corresponding foreign variables. To do so, we used both the Augmented Dickey Fuller (ADF) test as well as the Weighted-Symmetric Dickey Fuller (WS) test. The WS test exploits the time reversibility of stationary autoregressive processes in order to increase their power performance, as originally suggested by Park and Fuller (1995). ${ }^{2}$ The lag length was selected according to the Bayesian-Schwartz (BS) criterion. Unit root tests were conducted for all domestic and foreign variables, where we included an intercept and a time trend. The results are shown in Table 1. As expected, there is a mix of stationary and non-stationary variables with most of the data falling into the latter category. All nonstationary data are integrated of order 1. Given that most of the time series are non-stationary, Johansen's cointegration test was conducted in order to determine the number of cointegrating relationships for each region, where a deterministic trend was allowed for in the cointegration space. Based on the trace statistic, we found one cointegrating relationship for all regions except for Europe where we found two.

\footnotetext{
${ }^{2}$ Authors like Leybourne et al. (2005) and Pantula et al. (1994) provide evidence of the superior performance of the WS test compared to the ADF test.
} 
[Table 1 about here]

Our VARX models each contain 9 variables. For all regions other than the US, these consist of 4 region-specific time series (EX, IM, GDP, REER) and 5 foreign series corresponding to the rest-of-the-world averages of EX, IM, GDP and REER as well as the global variable OIL. Following Dees et al. (2007) and Bussiére et al. (2012) we include OIL as a fifth endogenous variable in the VARX for the US only. The order of the region-specific VARX $\left(q_{i}, q_{i}^{*}\right)$ models was chosen using the BS criterion, where a VARX $(2,1)$ was selected for all regions except for the group of European countries, where a VARX $(1,1)$ is the preferred specification.

The GVAR model requires the region-specific foreign variables $\boldsymbol{x}_{i, t}^{*}$ to be weakly exogenous. In general, a variable in a VARX model is considered weakly exogenous (or long-run forcing) if there is no long-run feedback from $\boldsymbol{x}_{i, t}$ to $\boldsymbol{x}_{i, t}^{*}$, without necessarily ruling out lagged short run feedback between the two sets of variables. As suggested by Johansen (1992), weak exogeneity can be determined by testing the joint significance of the estimated error correction terms in auxiliary equations of the region-specific foreign variables $\boldsymbol{x}_{i, t}^{*}$. To this end we run separate regressions for each $l^{\text {th }}$ element of $\boldsymbol{x}_{i, t}^{*}$ of the form:

$$
\Delta x_{i t, l}^{*}=a_{i, l}+\sum_{k=1}^{r_{i}} \delta_{i k, l} E \widehat{C M_{i k, t}-1}+\sum_{m=1}^{q_{i}} \boldsymbol{\varphi}_{i m, l}^{\prime} \Delta \boldsymbol{x}_{i, t-m}+\sum_{n=1}^{q_{i}^{*}} \boldsymbol{\psi}_{i n, l}^{\prime} \Delta \boldsymbol{x}_{i, t-n}^{*}+\eta_{i t, l}
$$

where the $E \widehat{E M_{i k, t-1}}$ for $k=1, \ldots, r_{i}$ are the estimated error correction terms corresponding to the $r_{i}$ cointegrating relations found for the $i^{\text {th }}$ region, and $q_{i}$ and $q_{i}^{*}$ are the orders of the lagged rates of change for the domestic and foreign variables respectively. The weak exogeneity test is an F-test of the joint hypothesis that $\delta_{i k, l}=0$ for $k=1, \ldots, r_{i}$ in the above equation. The lag orders of $q_{i}$ and $q_{i}^{*}$ are selected using the BS criterion, and are 
not necessarily the same as those of the underlying region-specific models. The results are reported in Table 2, where all variables for all regions pass the test. We have also checked the dynamic stability of the GVAR model of Eq. (8) by ascertaining that all its eigenvalues lie on or inside the unit circle.

[Table 2 about here]

Finally, we follow Bussiére et al. (2012) in conducting a battery of structural break tests to check for potential instability of the model parameters over time, the results of which are summarized in Table 3. In particular, we applied the Ploberger-Krämer maximal CUSUM statistic PKsup and the related mean square statistic PKmsq based on cumulative forecast errors, the Nyblom test for time-varying parameters and its heteroscedasiticityrobust variant, as well as tests based on sequential Wald statistics for a single break at an unknown change point. These are the Quandt likelihood ratio statistic (QLR) and Hansen's mean Wald statistic (MW), as well as their heteroscedasiticity-robust variants ${ }^{3}$. All tests indicate parameter stability at least at the $90 \%$ level, and in most cases at the $95 \%$ level $^{4}$.

[Table 3 about here]

Identification of shocks is a major issue in GVAR models. In order to conduct dynamic

\footnotetext{
${ }^{3}$ Stock and Watson (1996) provide a detailed description and analysis of the various structural stability tests.

${ }^{4}$ To further check the robustness of the model around the financial crisis of 2007-08, we conducted the same structural stability tests for a shorter sample of 1997Q2-2012Q4 (leaving out five years from both the beginning and the end of the sample). The results again indicate parameter stability at least at the $90 \%$ level, implying that the model is robust to the economic changes of that period. Details of the test results are available from the authors upon request.
} 
analysis, the vast majority of the research papers using GVAR models rely on generalized impulse response functions (GIRFs) as proposed by Koop et al. (1996) and further developed by Pesaran and Shin (1998). In contrast to the standard impulse response analysis of the traditional VAR literature, GIRFs integrate out the effects of shocks to individual variables on the basis of the observed residual covariance matrix without having to rely on orthogonalization. This makes the GIRFs invariant to the ordering of countries and variables, which is a desirable feature for the GVAR setting in which both the high dimensionality of the model and the presence of cross-country interactions may make a theory-led ordering of the variables difficult. At the same time, the fact that the error terms are not orthogonalized implies that the GIRFs are potentially mutually correlated, rendering their structural interpretation problematic.

This problem can be alleviated by resorting to structural generalized impulse response functions (SGIRFs) which allow for a particular ordering of variables for the dominant country, which is the US in our model. The SGIRFs are invariant to the ordering of the other countries and variables in the model. Based on the lower-triangular Cholesky decomposition, we choose the ordering [GDP, EX, IM, REER, OIL]' for the US. ${ }^{5}$ Table 4 reports the cross-regional correlation coefficients of the residuals of the country-group models. It turns out that there is no evidence of any substantial correlation in the residuals, implying that the individual SGIRFs of our model are not much affected by the other shocks in the system.

[Table 4 about here]

\footnotetext{
${ }^{5}$ Our results are robust to variations in the ordering of the trade volume and relative prices variables.
} 


\section{Results}

We report the SGIRFs for a contractionary one-standard-deviation shock to US imports, corresponding to a drop of about 2 percent relative to its pre-shock level in the long run $^{6}$. These are displayed in Fig. 2, where we report the bootstrap median estimates and the associated $90 \%$ bootstrap confidence bands computed on the basis of 1000 replications of the SGIRFs, where the forecast horizon extends up to 20 quarters and is recorded along the horizontal axis.

[Figure 2 about here]

Fig. 2 shows the dynamic transmission of a negative one-standard-deviation shock to US import volumes, reaching 2 percent in the long run. This shock leads to significant secular declines of both export and import activity as well as GDP levels in all parts of the world. Export volumes recede in the longer run by about 1.5 percent in both EC and NE, and by 2 percent in US and EE. At the same time, GDP levels fall by $0.4,0.6,0.35$ and 0.5 percent in US, EC, NE and EE respectively. The GDP drop is most drastic in EC and is most probably due to the sizable trade openness of these countries. The lower GDP levels give rise to the observed declines of import activity in the individual regions, with about 2 percent each in

\footnotetext{
${ }^{6}$ Depending on the specific set of trade policy measures implemented by the US government, the actual size of the contractionary impulse may be a multiple of the standardized shock analyzed in this paper, with the responses of all variables scaled up by the respective multiple. For example, Yalcin et al. (2017) simulate the expected impact of the protectionist measures contemplated by the Trump administration. Assuming the US to increase customs duties on imports vis-a-vis all other WTO member countries by 20 percent relative to the prevailing tariff levels results in a drop of US imports of between 20 and 30 percent. This figure rises to between 50 and 60 percent in a scenario in which the US is assumed to raise both tariffs and non-tariff barriers by 20 percent across the board.
} 
the US as well as EC and NE, and close to 3 percent in EE. The trade balance effect as the difference between exports and imports is negative in all regions other than the US where it remains essentially unchanged. Finally, we find no significant real exchange rate responses in any of the world regions.

Any trade restrictions imposed by the US run the risk of being reciprocated by its trading partners in equal measure. We simulate such a trade war scenario by considering a reduction in import volumes of comparable size to the US trade restriction, implemented simultaneously in all regions of the world. To this end, we aggregate the individual regions into a rest of the world (ROW) super region. The results are reported in Fig. 3.

[Figure 3 about here]

We consider a negative one-standard-deviation reduction to ROW imports. This translates into a long-run import decline of 2 percent, and is thus quantitatively comparable to the US trade shock analyzed above. As in the previous scenario, we again find that export and import activity as well as GDP levels fall both in the US and in the rest of the world. However, in contrast to the US trade shock scenario, the resulting effects are now strongest in the short run, reaching their respective maxima at the 4-quarter forecast horizon. In particular, ROW exports decline by 2 percent and imports by 3 percent one year after the occurrence of the trade shock, giving rise to an improvement in the trade balance of 1 percent at the 4-quarter horizon. Export and import volumes recuperate somewhat thereafter, but remain below their pre-shock levels throughout. In particular, export volumes are still 1 percent lower after 20 quarters, although the associated impulse response function becomes insignificant at a horizon of 6 quarters. In contrast, the impulse response for ROW imports stays significant and reverts to minus 2 percent in the longer run. This implies that the trade 
balance remains significantly positive for the ROW country block even in the long run.

Turning to the evidence for the US, export and import volumes decline respectively by 6 and 2.5 percent at 4 quarters, implying a trade deficit of 3.5 percent at the one-year forecast horizon. Whereas import volumes are still 1.5 percent lower than their pre-shock level in the long run, the associated SGIRF becomes insignificant after 6 quarters. In contrast, the long-run effect on exports remains significant throughout, with a decline of 4 percent after 20 quarters. Therefore the initial US trade deficit is maintained both in the short and in the long run.

The ROW import shock also results in significant exchange rate responses. In particular, the REER shows a significant and permanent depreciation of up to 2 percent in ROW and a rather marked impact appreciation of 5 percent in the US, which reaches 8 percent in the long run. These REER effects give rise to expenditure switching responses by making US exports less competitive compared to ROW exports, and thus partly accounting for the trade balance effects discussed above.

Finally, GDP levels in the US and ROW fall respectively by 0.4 and 0.8 percent one year after the occurrence of the trade shock, although these responses become insignificant in the longer run. This implies that in terms of the GDP response, the rest of the world is initially much harder hit by the imposition of the retaliatory trade measures compared to the US.

\section{Conclusions}

This paper employs a global vector autoregression (GVAR) model to analyze the international transmission and international repercussions of US trade policy shocks. These are modeled as a general reduction of US import volumes. We consider 25 countries in the 
rest of the world, grouped into larger regions comprising European nations, non-European industrial countries and emerging economies. Apart from real exports and imports, we also include real output and the effective real exchange rate representing the demand and relative price terms respectively, and the price of oil as a global variable. Using quarterly data for the period 1992Q1 to 2017Q4, we find that a negative shock to US imports reduces trade volumes and income levels in the rest of the world as well as in the US itself. The trade balance is negatively affected in all world regions except in the US where it remains essentially unchanged. We also find no significant real exchange rate effects.

We go on to model the effects of a trade war in which the rest of the world responds in equal measure to the trade restrictions imposed by the US. We again find that export and import activity recedes both in the US and in the rest of the world, although the resulting effects are now strongest in the short run. We also find that the trade balance improves in the rest of the world but deteriorates in the US. These effects are at least partly driven by the real exchange rate response, which shows an appreciation in the US and a depreciation in the rest of the world. Finally, we find that in the short run, GDP levels fall in the US but much more so in the rest of the world. Although these responses become insignificant in the longer run, this evidence implies that in terms of the GDP response, the rest of the world is initially much harder hit by the imposition of the retaliatory trade measure than is the US. 


\section{References}

Bussiére, M., Chudik, A., and Sestieri, G. (2012). Modelling global trade flows: Results from a GVAR model. Globalization and Monetary Policy Institute Working Paper No. 119, Dallas, TX: Federal Reserve Bank of Dallas.

Chudik, A. and Pesaran, M. (2016). Theory and practice of GVAR modelling. Journal of Economic Surveys, 30(1):165-197.

Dees, S., Holly, S., Pesaran, M. H., and Smith, L. (2007). Long run macroeconomic relations in the global economy. Economics - The Open-Access, Open-Assessment E-Journal, 1(2007-3):1-58.

Dovern, J. and van Rohe, B. (2014). International transmission and business-cycle effects of financial stress. Journal of Financial Stability, 13:1-17.

Eickmeier, S. and Ng, T. (2015). How do US credit supply shocks propagate internationally? A GVAR approach. European Economic Review, 74:128-145.

Fadejeva, L., Feldkircher, M., and Reininger, T. (2017). International spillovers from Euro area and US credit and demand shocks: A focus on emerging Europe. Journal of International Money and Finance, 70(C):1-25.

Feldkircher, M. and Huber, F. (2016). The international transmission of US shocks - evidence from Bayesian global vector autoregressions. European Economic Review, 81:167-188.

Greenwood-Nimmo, M., Nguyen, V., and Shin, Y. (2012). Probabilistic forecasting of output growth, inflation and the balance of trade in a GVAR framework. Journal of Applied Econometrics, 27(4):554-573. 
Johansen, S. (1992). Cointegration in partial systems and the efficiency of single-equation analysis. Journal of Econometrics, 52(3):389-402.

Koop, G., Perasan, H., and Potter, S. (1996). Impulse response analysis in nonlinear multivariate models. Journal of Econometrics, 74(1):119-147.

Leybourne, S., Kim, T., and Newbold, P. (2005). Examination of some more powerful modifications of the Dickey-Fuller test. Journal of Time Series Analysis, 26(3):355-369.

Pantula, S. G., Gonzalez-Farias, G., and Fuller, W. A. (1994). A comparison of unit-root test criteria. Journal of Business \& Economic Statistics, 12(4):449-459.

Park, H. and Fuller, W. (1995). Alternative estimators and unit root tests for the autoregressive process. Journal of Time Series Analysis, 16(4):415-429.

Pesaran, M. H., Schuermann, T., and Weiner, S. M. (2004). Modelling regional interdependencies using a global error-correcting macroeconometric model. Journal of Business \& Economics Statistics, 22:129-162.

Pesaran, M. H. and Shin, Y. (1998). Generalized impulse response analysis in linear multivariate models. Economics Letters, 58(1):17-29.

Stock, J. and Watson, M. (1996). Evidence on structural instability in macroeconomic time series relations. Journal of Business and Economic Statistics, 14(1):11-30.

Yalcin, E., Felbermayr, G., and Steininger, M. (2017). Global impact of a protectionist U.S. trade policy. Ifo Institute Research Paper No. 89, Munich: Ifo Institute. 


\section{Appendix}

\subsection{Figures and tables}

Table 1: Unit root tests

\begin{tabular}{|c|c|c|c|c|c|c|}
\hline \multicolumn{7}{|c|}{ Domestic variables } \\
\hline Domestic Variables & Statistic & Critical Value & US & $\mathrm{EC}$ & $\mathrm{NE}$ & $\mathrm{EE}$ \\
\hline \multirow[t]{2}{*}{ GDP } & $\mathrm{ADF}$ & -3.45 & -1.96 & -2.09 & -2.26 & -1.46 \\
\hline & WS & -3.24 & -1.08 & -2.16 & -1.09 & -1.77 \\
\hline \multirow[t]{2}{*}{$\mathrm{EX}$} & $\mathrm{ADF}$ & -3.45 & -2.54 & -2.24 & -2.62 & -2.12 \\
\hline & WS & -3.24 & -2.70 & -1.92 & -1.80 & -2.18 \\
\hline \multirow[t]{2}{*}{$\mathrm{IM}$} & $\mathrm{ADF}$ & -3.45 & -2.28 & -2.21 & -2.97 & -3.24 \\
\hline & WS & -3.24 & -1.34 & -2.00 & -2.65 & -3.06 \\
\hline \multirow[t]{2}{*}{ REER } & $\mathrm{ADF}$ & -3.45 & -1.51 & -1.97 & -1.89 & -2.33 \\
\hline & WS & -3.24 & -1.73 & -2.21 & -2.17 & -2.52 \\
\hline \multicolumn{7}{|c|}{ Foreign Variables } \\
\hline \multirow[t]{2}{*}{ GDP } & $\mathrm{ADF}$ & -3.45 & -3.13 & -2.43 & -2.79 & -3.27 \\
\hline & WS & -3.24 & -3.23 & -2.32 & -2.55 & -2.81 \\
\hline \multirow[t]{2}{*}{$\mathrm{EX}$} & $\mathrm{ADF}$ & -3.45 & -2.87 & -3.62 & -3.73 & -3.04 \\
\hline & WS & -3.24 & -2.54 & -2.98 & -3.25 & -1.83 \\
\hline \multirow[t]{2}{*}{ IM } & $\mathrm{ADF}$ & -3.45 & -3.48 & -2.23 & -2.19 & -2.34 \\
\hline & WS & -3.24 & -3.25 & -2.56 & -2.55 & -2.55 \\
\hline \multirow[t]{2}{*}{ REER } & $\mathrm{ADF}$ & -3.45 & -1.78 & -2.45 & -2.75 & -2.08 \\
\hline & WS & -3.24 & -1.98 & -2.67 & -2.96 & -2.19 \\
\hline \multicolumn{7}{|c|}{ Global variable } \\
\hline \multirow[t]{2}{*}{ OIL } & $\mathrm{ADF}$ & -3.45 & -1.77 & & & \\
\hline & WS & -3.24 & -2.02 & & & \\
\hline
\end{tabular}


Table 2: Weak exogeneity tests

\begin{tabular}{lrrllrl}
\hline Country & Critical value & GDP & EX & IM & REER & OIL \\
\hline US & 3.48 & 0.36 & 0.96 & 3.29 & 0.85 & 0.11 \\
EC & 3.11 & 0.37 & 0.95 & 3.12 & 0.75 & 0.08 \\
NE & 3.97 & 0.85 & 0.56 & 1.19 & 0.11 & 2.15 \\
EE & 3.95 & 1.35 & 2.35 & 0.53 & 1.05 & 2.57 \\
\hline
\end{tabular}

Notes: Tests for weak exogeneity at the $5 \%$ significance level. See Notes to Table 1 for abbreviations of countries and variables. 
Table 3: Structural stability tests

\begin{tabular}{|c|c|c|c|c|}
\hline & GDP & EX & IM & REER \\
\hline \multicolumn{5}{|c|}{ PK sup } \\
\hline US & $0.77^{* *}(1.34)$ & $0.79 * *(1.37)$ & $0.88^{*}$ & $0.69^{* *}(1.23)$ \\
\hline EC & $0.62 * *(0.84)$ & $0.59^{* *}(0.78)$ & $0.50 * *(0.86)$ & $0.83^{* *}(1.03)$ \\
\hline $\mathrm{NE}$ & $1.01^{* *}(1.11)$ & $0.81^{* *}(1.00)$ & $0.62^{* *}(1.01)$ & $0.86^{* *}(0.95)$ \\
\hline $\mathrm{EE}$ & $0.72^{* *}(1.14)$ & $0.90 *(0.82)$ & $1.05 *(0.85)$ & $0.42^{* *}(1.06)$ \\
\hline \\
\hline US & $0.09 * *(0.57)$ & $0.13 * *(0.52)$ & $0.14^{* *}(0.36)$ & $0.09^{* *}(0.45)$ \\
\hline EC & $0.06^{* *}(0.16)$ & $0.03^{* *}(0.15)$ & $0.04^{* *}(0.14)$ & $0.06^{* *}(0.30)$ \\
\hline $\mathrm{NE}$ & $0.17^{* *}(0.38)$ & $0.15^{* *}(0.36)$ & $0.04^{* *}(0.28)$ & $0.15^{* *}(0.22)$ \\
\hline $\mathrm{EE}$ & $0.09^{* *}(0.38)$ & $0.13^{*}(0.12)$ & $0.25^{*}(0.15)$ & $0.03^{* *}(0.25)$ \\
\hline \multicolumn{5}{|c|}{ Nyblom } \\
\hline US & $1.15^{* *}(2.68)$ & $1.99 * *(2.61)$ & $1.67^{* *}(2.29)$ & $1.99 * *(2.28)$ \\
\hline EC & $2.09^{*}(1.87)$ & $1.88^{* *}(1.88)$ & $1.62^{* *}(1.78)$ & $1.42^{* *}(2.13)$ \\
\hline $\mathrm{NE}$ & $1.59^{* *}(2.21)$ & $1.88^{* *}(5.06)$ & $2.29 * *(4.69)$ & $1.44^{* *}(2.09)$ \\
\hline $\mathrm{EE}$ & $1.86^{* *}(2.21)$ & $2.70 *(2.27)$ & $3.22^{*}(2.29)$ & $1.54^{* *}(2.23)$ \\
\hline \multirow{2}{*}{\multicolumn{5}{|c|}{ Robust Nyblom }} \\
\hline & & & & $1.76^{* *}(2.54)$ \\
\hline $\mathrm{EC}$ & $1.36 * *(2.03)$ & $1.51^{* *}(1.94)$ & $1.51^{* *}(2.03)$ & $1.75^{* *}(2.10)$ \\
\hline $\mathrm{NE}$ & $1.74^{* *}(2.41)$ & $2.51^{* *}(3.89)$ & $2.20 * *(3.98)$ & $1.58^{* *}(2.36)$ \\
\hline $\mathrm{EE}$ & $1.96 * *(2.39)$ & $2.37^{* *}(2.75)$ & $2.47^{* *}(2.77)$ & $1.78 * *(2.54)$ \\
\hline & & $2700 * *(25 \stackrel{\mathrm{Q}}{2}$ & & \\
\hline ES & $\begin{array}{l}17.79^{* *}(34.21) \\
3056 *(2626)\end{array}$ & $27.20^{* *}(35.38)$ & $24.96^{* *}(29.05)$ & $26.53^{* *}(28.75)$ \\
\hline $\mathrm{NE}$ & $\begin{array}{l}59.50 * *(30.20) \\
20.08 * *(31.53)\end{array}$ & $\begin{array}{l}23.44 * *(93.04) \\
26.79^{* *}(93.17)\end{array}$ & $\begin{array}{l}30.58 \\
47.38^{* *}(76.45)\end{array}$ & $\begin{array}{l}19.00^{*} \\
37.43\end{array}$ \\
\hline $\mathrm{EE}$ & $38.03^{*}(32.51)$ & $72.22 *(30.30)$ & $70.19 *(30.60)$ & $26.15^{* *}(31.07)$ \\
\hline \multirow{2}{*}{\multicolumn{5}{|c|}{ Robust QLR }} \\
\hline US & & $20.51^{* *}(24.97)$ & $16.16^{* *}(22.02)$ & $16.49^{* *}(22.77)$ \\
\hline $\mathrm{EC}$ & $13.08^{* *}(20.65)$ & $19.27^{* *}(19.9$ & $15.47^{* *}(19.73)$ & $19.35^{* *}(21.45)$ \\
\hline $\mathrm{NE}$ & $16.09 * *(23.43)$ & $26.76^{* *}(34.99)$ & $23.75^{* *}(34.56)$ & $19.02^{* *}(22.40)$ \\
\hline $\mathrm{EE}$ & $15.87^{* *}(21.69)$ & $28.20 *(24.36)$ & $20.55^{* *}(23.36)$ & $14.87^{* *}(22.48)$ \\
\hline \multicolumn{5}{|c|}{ MW } \\
\hline US & $8.93^{* *}(20.18)$ & $15.71^{* *}(19.5$ & $12.86^{* *}(16.35)$ & $14.53^{* *}(16.97)$ \\
\hline EC & $14.84^{*}(13.85)$ & $14.57^{*}(13.63)$ & $\begin{array}{l}12.60^{* *}(13.02) \\
25.27^{* *}(43.05)\end{array}$ & $\begin{array}{l}11.24^{* *}(16.97) \\
12.40^{* *}(15.45)\end{array}$ \\
\hline $\mathrm{NE}$ & $11.68^{* *}(17.16)$ & $15.61^{* *}(49.55)$ & $25.27^{* *}(43.95)$ & $12.40^{* *}(15.45)$ \\
\hline $\mathrm{FF}$ & $15.07^{* *}(16.84)$ & $23.87^{*}(16.53)$ & $28.64^{*}(17.55)$ & $10.25^{* *}(16.50)$ \\
\hline \multicolumn{5}{|c|}{ Robust MW } \\
\hline EC & $9.82^{* *}(12.61)$ & $11.11^{* *}(12.32)$ & (12.6) & $12.15 * *(13$. \\
\hline $\mathrm{NE}$ & $11.98 * *(15.60)$ & $17.44^{* *}(23.26)$ & $17.38 * *(22.84)$ & $10.94^{* *}(14.99)$ \\
\hline $\mathrm{EE}$ & $11.97^{* *}(14.82)$ & $16.86^{*}(16.11)$ & $15.57^{*}(15.99)$ & $11.43^{* *}(15.61)$ \\
\hline
\end{tabular}

Notes: Test statistics for structural stability of parameters. The null hypothesis is parameter constancy, where $*$ and ** indicate significance at the $90 \%$ and $95 \%$ level. Critical values at the $95 \%$ in parentheses. See Notes to Table 1 for abbreviations of countries and variables, and the main text for 0 he various stability tests. 
Table 4: Average pairwise cross-regional correlations of residuals

\begin{tabular}{|l|l|l|l|l|}
\hline & US & EC & NE & EE \\
\hline GDP & -0.02 & 0.13 & 0.16 & -0.01 \\
\hline EX & -0.11 & -0.01 & -0.11 & -0.24 \\
\hline IM & 0.00 & -0.02 & -0.06 & -0.16 \\
\hline REER & -0.07 & -0.01 & -0.02 & 0.14 \\
\hline
\end{tabular}

Notes: The table reports the average pairwise cross-regional correlation coefficients of the VARX residuals for each individual region with respect to the averages of the other regions in the sample. See Notes to Table 1 for abbreviations of countries and variables. 

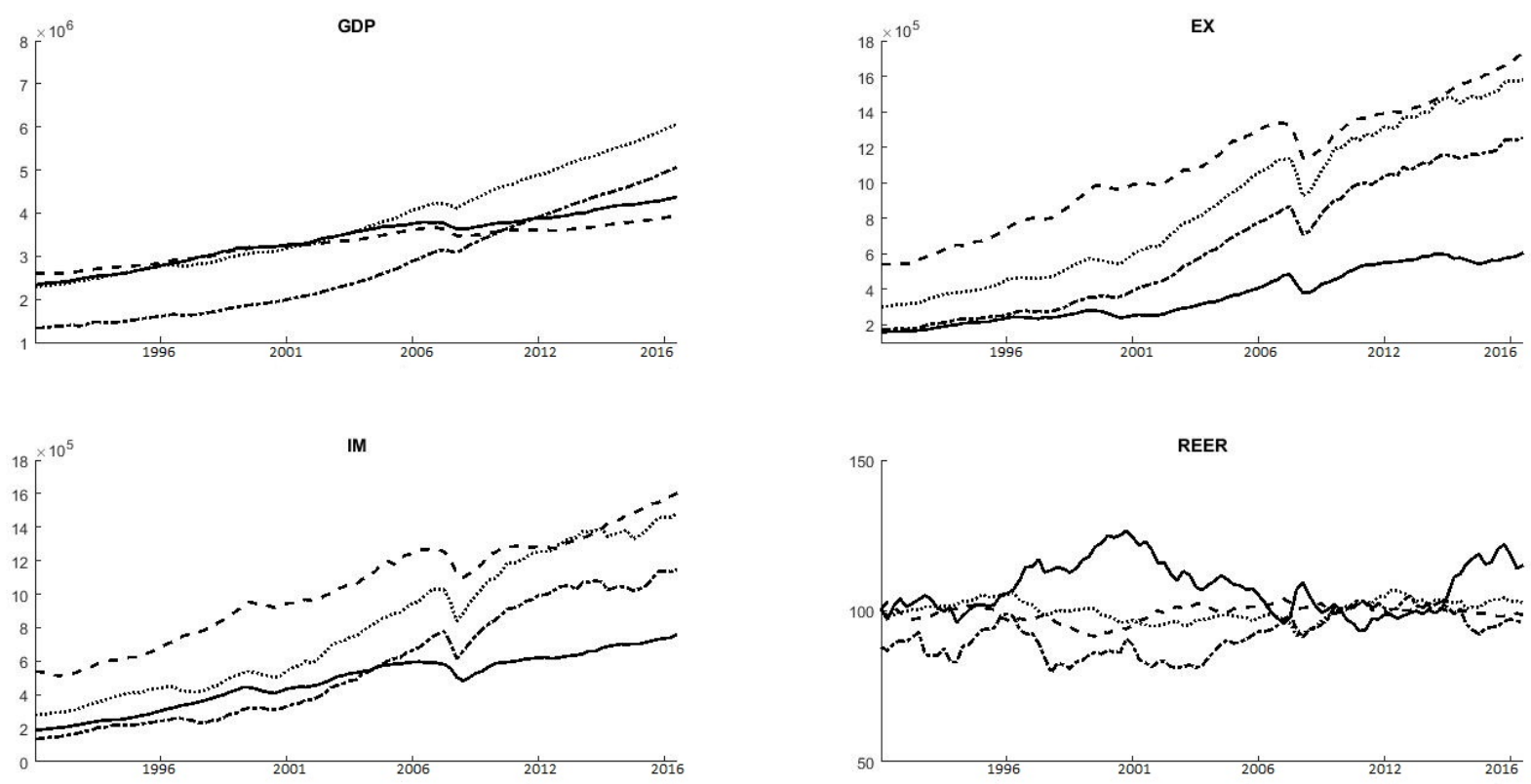

Figure 1: GDP, real exports and imports, and effective real exchange rates.

Notes: See Notes to Table 1 for abbreviations of countries and variables. GDP, EX and IM are expressed in million U.S. dollars, REER index with 2010Q1=100. 

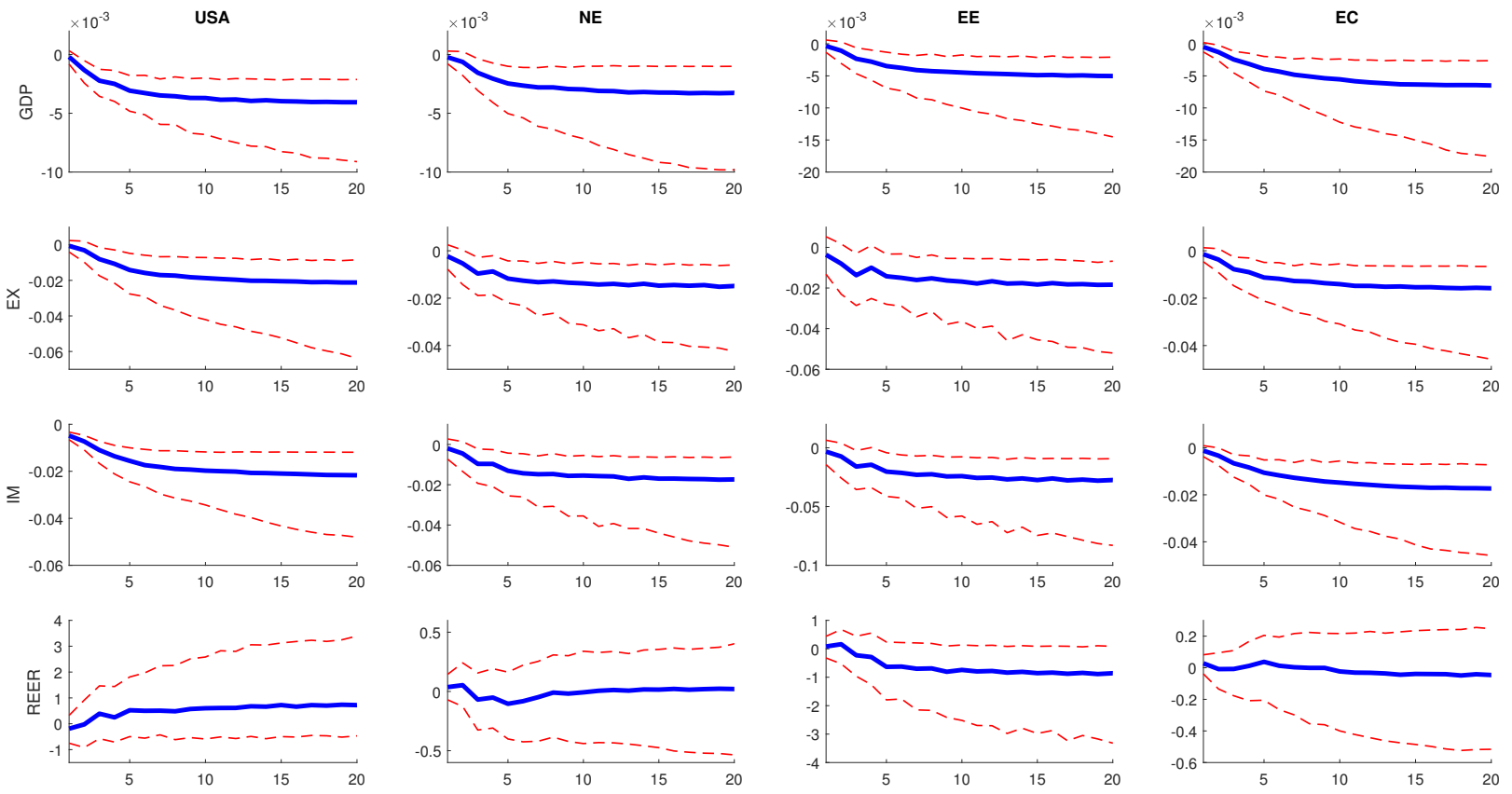

Figure 2: Impulse response functions for a negative US trade shock

Notes: See Notes to Table 1 for abbreviations of countries and variables. The Figure reports structural general impulse response functions (SGIRFs) following a one-standard-deviation negative shock to US import volumes.

The graphs show bootstrap median estimates (non-cumulative) with the associated $90 \%$ bootstrap confidence bands computed on the basis of 1000 replications, where the forecast horizon extends up to 20 quarters and is recorded along the horizontal axis. 

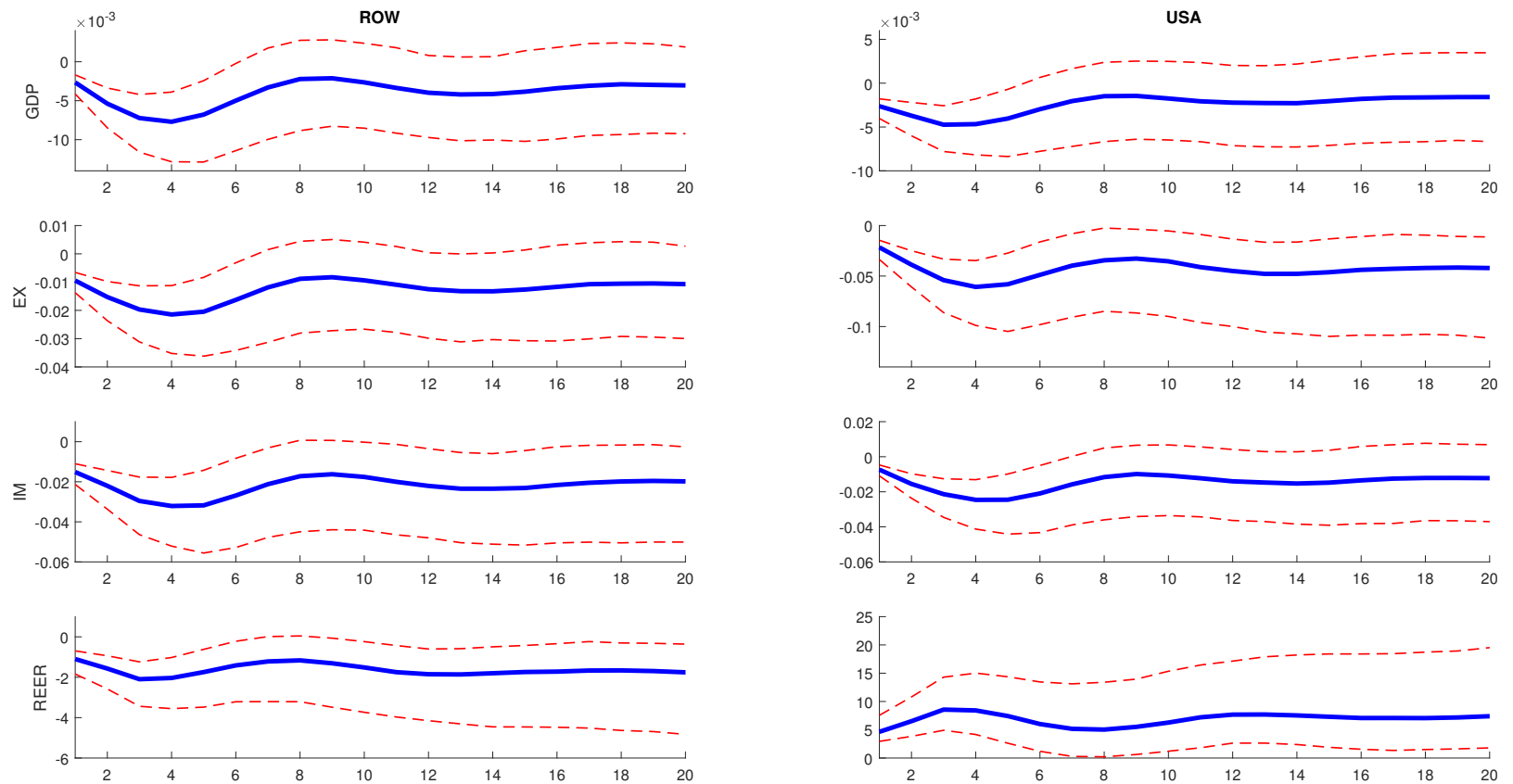

Figure 3: Impulse response functions for a negative trade shock in the rest of the world. Notes: see Fig.2. 